\title{
Predator-Prey Relationships in the Southeastern Ozarks-A.D. 1300
}

\author{
Bruce D. Smith ${ }^{1,2}$ \\ Received November 10, 1971; revised August 19, 1973
}

Archeological findings provide the basis for analyzing the exploitation of deer by Powers Phase Indian hunters in the southeastern Ozarks circa A.D. 1300. Predatory patterns of wolves have been documented. It is hypothesized that men and wolves were complementary, noncompetitive predators and that their predation functioned to keep the deer population within the carrying capacity of the southeastern Ozarks. $A$ model is developed to illustrate the predator-prey relationships in the area.

\section{INTRODUCTION}

What relations are possible between predators and prey in ecosystems in which man is but one of the predators? This study examines specifically the predator-prey relationships among men, wolves, and deer in the southeastern Ozarks in A.D. 1300. Drawing on archeological data from the Snodgrass site, as well as ethnohistorical evidence from similar areas, we propose that predation by Powers Phase Indians ${ }^{3}$ and wolves (Canis lupus) was largely complementary and noncompetitive, and that it functioned to keep the deer population (Odocoileus virginianus) from crashing due to overbrowsing of the plant food base. To support this hypothesis, local plant communities, significant physical characteristics and seasonal habits of deer, and predatory patterns of wolves and men will be discussed.

The Powers Phase Research Project is financed by National Science Foundation Grant GS-3215 to James B. Griffin, University of Michigan.

'Museum of Anthropology, University of Michigan, Ann Arbor, Michigan.

${ }^{2}$ Present address: Department of Anthropology, Loyola University of Chicago, Chicago, Illinois.

${ }^{3}$ The term "Powers Phase" has been applied to a pre-Columbian American Indian population of Middle Mississippian cultural affiliation which occupied an area in southeast Missouri for a relatively short period of time circa A.D. 1300.

O1974 Plenum Publishing Corporation, 227 west 17 th Street, New York, N.Y. 10011. No part of this publication may be reproduced, stored in a retrleval system, or transmitted, in any form or by any means, electronic, mechanical, photocopying, microfilming, recording, or otherwise, without written permission of the publisher. 


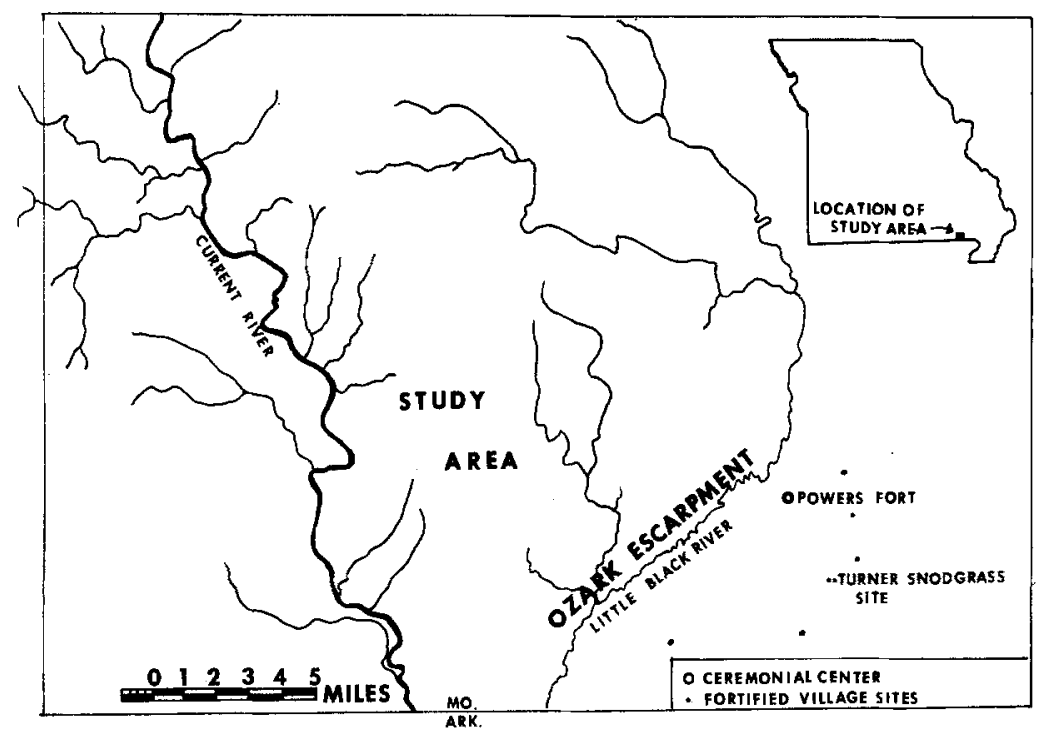

Fig. 1. Location of Powers Phase study area.

\section{THE SITE}

The settlements of Powers Phase Indians, circa A.D. 1300, were located at the extreme western edge of the Mississippi Valley, directly adjacent to the Ozark highlands. They consisted of a central ceremonial center, approximately 12 acres in area (Powers Fort), and a series of at least six fortified villages arranged in a semicircular pattern in the lowlands area to the east of the ceremonial center (Fig. 1).

Although it is estimated that the ceremonial center was occupied for a period of from 50 to 100 years, there is abundant archeological evidence to indicate that a number of the outlying villages were occupied for a much shorter period of time. The Snodgrass site (23 Bu 21B), which yielded the archeological sample of deer mandibles that is the basis of this study, is located on a ridge in the lowlands, immediately adjacent to the Ozark escarpment and represents such a short-term occupation.

\section{FOREST TYPE DISTRIBUTION}

The topography and distribution of soil types in the Ozark highlands area directly adjacent to the lowlands villages of the Powers Phase Indians have changed very little during the last few thousand years (Steyermark, 1959), the 
general pattern being one of small, well-drained ridge systems and irregular hilly areas with stony residual soils, interspersed quite regularly with small valleys or "hollows" containing silty soils which are constantly renewed. This distinctive landscape pattern largely determines the distribution of vegetation in the area.

A number of detailed studies have defined and described the distribution of the four main forest types that occur in the area (Segelquist and Green, 1968; Segelquist et al., 1969; Steyermark, 1940). These main types are generally distributed within the southeastern. Ozarks in the following way:

1. Upland hardwood-north and east exposure of ridge tops and upper slopes.

2. Upland pine-hardwood-south and west exposure of ridge tops and upper slopes.

3. Cedar glades-rocky outcrop areas on western and southern slopes.

4. Stream-bottom hardwood-narrow stream bottoms and lower slopes.

It is presumed that this pattern of forest type distribution is quite similar to that which existed 700 years ago, since it is determined largely by factors of drainage, soil type, and topography in this area, factors that have remained constant over a long period of time (Steyermark, 1959, has a more detailed discussion of this point).

\section{CHARACTERISTICS OF THE DEER POPULATION}

The physical characteristics of the white-tailed deer population now in the study area that are of most significance to our discussion are the approximate dates of fawn dropping and the commencement of antler development stages and of the rutting season. The peak of the fawn-dropping period is approximately the first of June (Dunkeson, 1958), with most births occurring in late May and the first 2 weeks of June. Antler growth begins around the middle of May, with some variation observed in both directions. Full antler development is usually attained by the end of July, but rubbing does not start until around the beginning of September, when antlers have fully hardened. Velvet rubbing lasts throughout September. This practice of polishing antlers is accentuated by the rut, and develops into a characteristically belligerent activity, bucks making fitful assaults on shrubbery as well as on each other. During the rutting season (late September through November), the antlers are in nearly perfect condition. Bucks use their antlers in frequent combat until the mating season is on the wane. Antlers are usually dropped between the middle of January and the first week of February.

During the rutting season, which peaks between November 1 and 10 , buck behavior becomes hectic and often violent. Bucks frequently attack other bucks, 


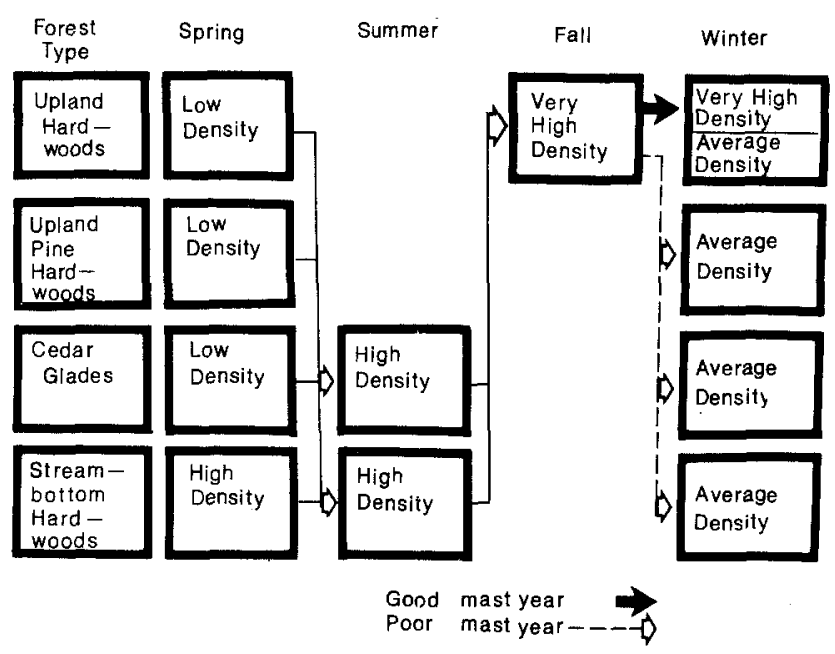

Fig. 2. Relative seasonal density of deer in the southeastern Ozarks.

and intently seek out does, two or more bucks sometimes following the same doe.

The white-tailed deer's other seasonal activities are associated with its feeding habits. It is a browsing ruminant, and its diet consists of tender shoots, twigs and leaves, a wide assortment of herbaceous foodstuffs, acorns of a number of oak species, and certain fruits. It is selective in its feeding habits, and the types of plants making up a deer's diet shift quite significantly and predictably from season to season.

Differential palatability applies not only to variation between plant species but also to variation in the same species at different stages of its development (a species may be highly favored in March, yet go untouched in July). Acorns are the single most important food item for deer in the study area (Korschgen, 1962: 167). As August ends, the deer quite abruptly shift their attention to the acorns that begin to litter the ground beneath various species of oaks. They will eat acorns almost exclusively for the next few months, and acorns will remain an important food source throughout the winter, until the appearance of the first green grasses of early March signals the start of a new feeding cycle.

Given the location and seasonal availability of vegetation, deer movements can be predicted with a high degree of accuracy. During the fall, when oak mast is abundant, the deer concentrate their feeding in upland hardwood areas. The extent to which they remain within this forest type during the winter is a function of the continuing availability of acorns. When the oak mast yield is abundant enough to provide sustenance throughout the winter, deer will remain in the upland hardwoods; when such yields are low, they are forced to shift to 
forage. When the latter condition prevails, their forest type preference changes and the deer browse throughout the forest types.

In the spring, the deer concentrate their feeding in the stream-bottom hardwood areas, feeding on early-emerging grasses and sedges. As the growing season progresses, deer expand their feeding range to include cedar glades and lower slopes. They continue feeding in these areas throughout the summer. It would seem evident, then, that deer concentrate consistently only during the periods of September-November (in the upland oak-hickory hardwoods) and March-April (in the stream-bottom hardwoods), with the fall concentration being the more reliable of the two (Fig. 2).

\section{GENERAL PREDATORY PATTERNS OF WOLVES AND MEN}

We are assuming here that predation of a specific nature functioned to keep the deer population of the southeastern Ozarks below the region's carrying capacity during the period in question. Yet it must be noted that the underlying assumption-that predation of a specific nature by specialized carnivores such as wolves and men is the primary inhibitory factor operating on herding ungulate populations in undisturbed situations-has been a point of debate for some years. While the argument has not been settled, a recent statement by $D$. $H$. Pimlott is of interest:

In considering the population dynamics of some big game species, deer and moose in particular, the question arises, as to why intrinsic mechanisms of population control have not evolved to prevent them from increasing beyond the sustaining level of their food supply. It seems reasonable to postulate that it may be because they have had very efficient predators, and the forces of selection have kept them busy evolving ways and means not of limiting their own numbers but of keeping abreast of mortality factors. (Pimlott, 1967, p. 275).

Commenting on Pimlott's statement, L. David Mech says, "If Pimlott's theory is correct, as I believe it is, wolf predation could very well have been the main limiting factor on most, if not all, big game before man so greatly disturbed the habitat" (Mech, 1970, p. 272).

It seems certain that wolves (Canis lupus) were present within the study area in A.D. 1300. Early historical accounts, as well as fairly recent kill records, attest to their abundance later in time, while the red wolf (Canis rufus) is still encountered in the study area.

If both wolves and Powers Phase Indian hunters were present in the area in A.D. 1300 , and if the white-tailed deer was a major food source for both, were they not, in fact, competing for the same food source? The relationship of these two predator types can better be understood through a consideration of the age composition of pre-Columbian deer harvests in Missouri, with specific reference to the Snodgrass site. 
By determining the ages of deer from mandibles recovered from archeological excavations, Elder (1965) determined the age composition of the deer harvests from three prehistoric sites in Missouri. His results are as follows:

1. Indians killed very few fawns-8\% or less of each sample.

2. Many deer survived into the older age groups; from 20 to $26 \%$ of the deer population was $6 \frac{1}{2}$ years old or more.

3. The maximum longevity was great, each sample showing some deer which had reached the age of 10 years or more (Elder, 1965, p. 368).

During the last 3 years of excavation at the Snodgrass site (1968-1970), a sample of 75 deer mandibles complete enough to be studied to determine the age of the animal from which they were taken was recovered. The age composition of the deer harvest represented by these mandibles is presented in Fig. 3 . This curve corresponds closely to the age composition curves obtained by Elder. Further, these age composition curves of pre-Columbian deer harvests are not only remarkably similar to each other, they are also extremely different from the age composition curves obtained from modern sport-hunting deer harvests:

1. Nearly one-third of the modern white man's bag is made up of fawns.

2. Very few deer live as long as $8 \frac{1}{2}$ years.

3. The proportion of all older deer, $6 \frac{1}{2}$ years or more, in the bag is again greatly reduced, to approximately $2 \%$ (Elder, 1965, p. 368).

Thus we see that Powers Phase hunters were obviously harvesting a quite different portion of the deer population in the study area than is being taken there today.

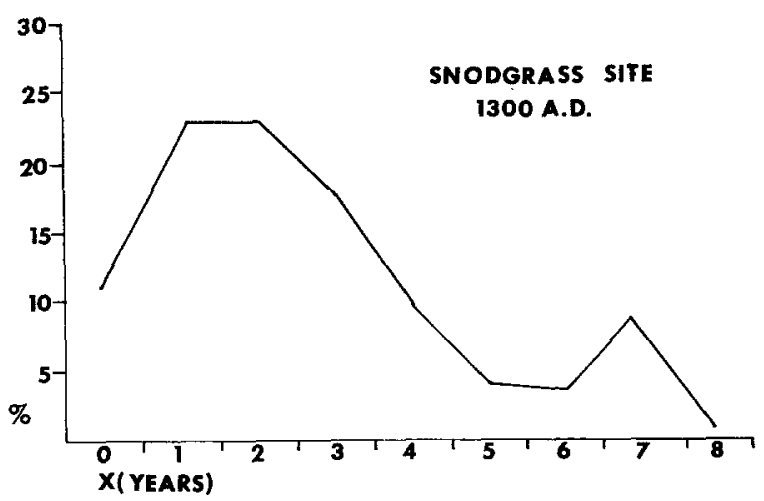

Fig. 3. Age composition of the deer kill from the Snodgrass site. 
One of the most interesting characteristics of the Powers Phase hunters' harvest is the low percentage of fawns (zero age class) represented in the kill. This is most unusual in that the young of the year are a large, highly vulnerable section of the deer population, and would seem to be highly susceptible to exploitation by predators.

Elder has attempted to find the most probable explanation for this characteristically low percentage of young of the year in pre-Columbian deer kills. Though he considered the possible influence of nonhuman predators such as Canis lupus and/or Canis rufus, he rejected their possible impact on the deer population in favor of the hypothesis that prehistoric cultures were practicing a "voluntary and effective conservation measure-sparing the fawns to grow into better hides and more meat" (Elder, 1965, p. 369).

However, a closer look at the selective nature of predation by wolves on deer populations strongly suggests that the impact of wolves, rather than any conscious conservation measure by human predators, was producing the low percentage of young of the year in the Powers Phase deer kill. It is well known that wolf populations characteristically exploit the zero age class in a prey population, along with the older, more vulnerable individuals. It was not until 1969 , however, that an accurate and detailed analysis of the selective pattern of wolf predation on an undisturbed deer population became available (Pimlott et al., 1969).

Pimlott's data concerning wolf predation patterns were obtained from a study of the wolf population in Algonquin Park, Ontario. With no sport hunting allowed, the primary mortality factors operating to control the growth of the deer population of the park were wolf predation, research sampling, and accidents. The age composition curve for wolf predation obtained by Pimlott can be considered as representative of the predation pattern of wolf populations in general and will therefore be projected as representative of the deer kill due to such predation in the study area in A.D. 1300.

The age distribution curve of wolf predation obtained by Pimlott is shown in Fig. 4 along with the age distribution curve of the deer harvest at the Snodgrass site. A comparison of these two curves indicates that there was very little direct competition between the two predator populations. (A Spearman rank correlation on the data yielded a 0.097 negative correlation between the two curves at a 0.001 level of significance.) The wolves and hunters apparently concentrated on almost mutually exclusive segments of the deer population. Man's role as a predator in the system can therefore be viewed as being complementary to that of the wolves.

Men and wolves were noncompetitive in their hunting practices as well. G. B. Schaller $(1972 a ; 1972 b)$ offers a description of a parallel relationship existing among lions, hyenas, and wildebeest on the Serengeti Plain of East Africa. As in the pre-Columbian case, the predator population which selects 


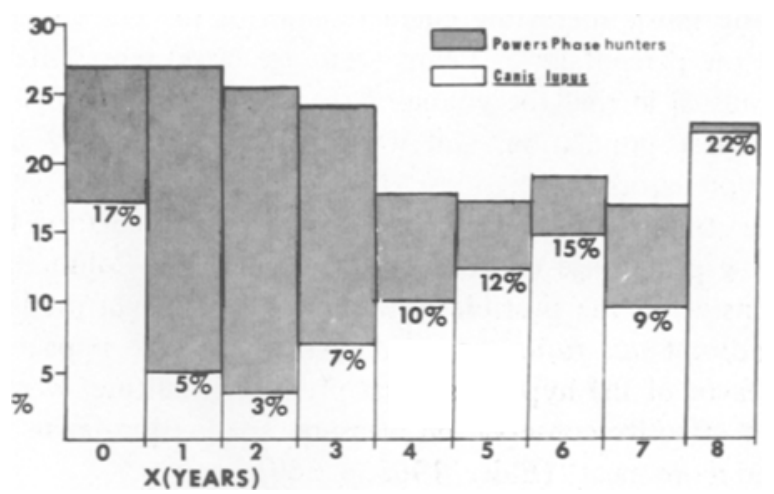

Fig. 4. A comparison of the age distribution of deer killed by Powers Phase hunters and the projected age distribution of deer killed by wolves (Canis lupus) in the southeastern Ozarks in A.D. 1300 (wolf curve adopted from Pimlott et al., 1969), showing noncompetitive, complementary nature of predation.

out the young of the year and the aged individuals are canids (hyenas) which hunt in groups by coursing techniques. Those exploiting the middle age classes (lions) use stalking techniques.

\section{POWERS PHASE INDIAN HUNTING PATTERNS}

Accepting the hypothesis that wolves and men in the study area were complementary and noncompetitive predators, we may now turn to the possible seasonality of human hunting patterns.

Although it is difficult to show the extent to which deer hunting was a seasonal activity, a strong case can be made to support the hypothesis that the Powers Phase Indians hunted deer principally during the fall and winter. As we have seen, the feeding habits and seasonal movements of deer in the area indicate that deer tend to concentrate in specific areas in the spring and late fall, the fall concentration in the upland hardwood areas being the more reliable of the two periods. It is almost certain that the Indians were aware of this concentration pattern and exploited it.

The concentration of deer in the fall coincides with the rutting season. From the time a buck's antlers drop their velvet (the first week in September) until the end of the rutting season (the last week in November), a "personality change" occurs which greatly increases the hunter's chances of getting close enough for a shot at the prey without being detected. During this period, the male deer changes so that it is no longer very wary but becomes overly curious 
and belligerent. This behavioral change seems to have been exploited in early historical times by human hunters, and was probably turned to practical account by the Powers Phase Indians as well.

Swanton (1946) cites nine ethnographic references to individual stalking of white-tailed deer by Indians in the southeast United States. Of these nine instances, eight made specific, detailed reference to the use of deer skins and/or heads both for concealment and to attract the deer. This tactic sometimes involved violent rustling of bushes and trees with stuffed deer heads held in the hunter's hand. Such a method closely simulates the way in which deer attack trees and bushes immediately prior to and during the rutting season.

This hunting strategy is one of slow stalking, concealment, and attraction of the deer prior to shooting. During most of the year, such a tactic would be unlikely to attract the prey but would, on the contrary, probably frighten it away. However, such is not the case from September to December. In one passage concerning this strategy, F. G. Speck refers to statements of Yuchi informants:

\begin{abstract}
My informants also remember this style of hunting. They said that, as it was usually undertaken in October or November when the bucks seek the does or seek each other to fight, either the head of a buck or the head of a doe could be used. Wonderful skill was claimed for some hunters. (Speck in Swanton, 1946, p. 317)
\end{abstract}

Evidence that the Powers Phase Indians actually did hunt deer intensively during the period from September to November--probably using techniques similar to those described above-can be obtained from an analysis of mandibles that come from deer less than 20 months old, which were found at the Snodgrass site. The eruption of permanent dentition and the replacement of deciduous premolars in Odocoileus virginianus during the first 20 months of life proceed at a relatively reliable rate. This fact permits investigators to assign individual mandibles of deer less than 20 months old to classes representing 2- to 3 -month age ranges (Severinghaus, 1949). Twenty-five mandibles of deer 20 months of age or younger, complete enough to be grouped in such 2- to 3-month classes, were recovered from the Snodgrass site (Table I).

In the southeastern Ozarks, the fawn-dropping period begins in late May. Fawning peaks about the first of June, and drops off slowly, ending about June 15. By taking June 1 as the date of birth of the 25 deer represented, an estimate of the date of death can be computed for each. Nineteen of the 25 deer were killed during the period from October 1 through February 1. A histogram of the seasonality of mortality of deer due to Powers Phase predation (Fig. 5) shows a single large peak which corresponds quite closely both to the availability of acorns in the upland hardwood areas and to the onset of the rutting season. The low mortality levels through the rest of the year suggest that although deer hunting was not solely a late fall and early winter activity, this was indeed the period of most intensive exploitation. 
Table I. Snodgrass Site-Age in Months of Alt Mandibles Less Than 20 Months

\begin{tabular}{cccc}
\hline Structure No. & Age in months & Winter kill? & Season of kill \\
\hline 1 & $17-20$ & Yes & Nov. 1-Feb. 1. \\
8 & $13-17$ & No & Jul. 1-Nov. 1. \\
16 & $4-9$ & Yes & Oct. 1-Mar. 1. \\
16 & $17-20$ & Yes & Nov. 1-Feb. 1. \\
17 & $17-20$ & Yes & Nov. 1-Feb. 1. \\
17 & $11-13$ & No & Mar. 1-Jul. 1. \\
19 & $17-20$ & Yes & Nov. 1-Feb. 1 \\
21 & $17-20$ & Yes & Nov. 1-Feb. 1 \\
21 & $9-11$ & No & Mar. 1-May 1 \\
23 & $17-20$ & Yes & Nov. 1-Feb. 1 \\
23 & $4-7$ & Yes & Oct. 1-Jan. 1 \\
24 & $17-20$ & Yes & Nov. 1-Feb. 1 \\
26 & $17-20$ & Yes & Nov. 1-Feb. 1 \\
42 & $17-20$ & Yes & Nov. 1-Feb. 1 \\
43 & $9-11$ & No & Mar. 1-May 1 \\
44 & $17-20$ & Yes & Nov. 1-Feb. 1 \\
44 & $17-20$ & Yes & Nov. 1-Feb. 1 \\
44 & $17-20$ & Yes & Nov. 1-Feb. 1 \\
46 & $17-20$ & Yes & Nov. 1-Feb. 1 \\
47 & $7-9$ & No & Jan. 1-Mar. 1 \\
47 & $17-20$ & Yes & Nov. 1-Feb. 1 \\
55 & $17-20$ & Yes & Nov. 1-Feb. 1 \\
82 & $17-20$ & Yes & Nov. 1-Feb. 1 \\
84 & $17-20$ & Yes & Nov. 1-Feb. 1 \\
Refuse pits & & & \\
34 & $11-13$ & No & May 1-Jul. 1 \\
Winter kill/total kill & & & \\
ratio & & $19 / 25$ & \\
\hline & & & \\
\hline
\end{tabular}

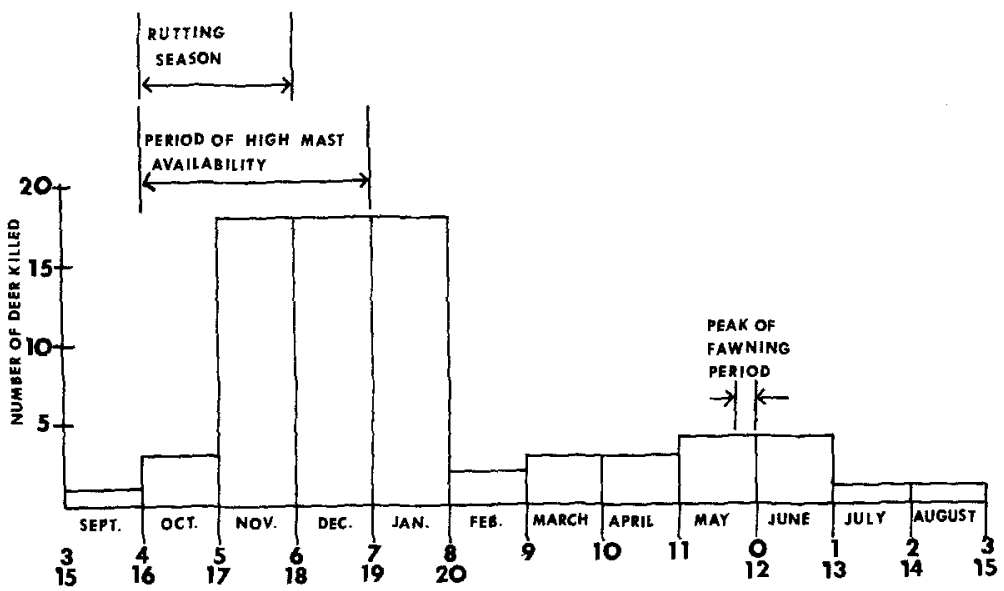

Fig. 5. Correlation between presumed season of deer harvest, the rutting season, and oak mast availability. 


\section{CONCLUSIONS}

The relationship that existed among predators, prey, and the vegetation food source of the prey species can be seen as a systemic one. This implies a model of homeostasis in which the principle of "negative feedback" explains the propensity of the system to compensate for disruptions of equilibrium. Such a system can be considered as being functional, in that it maintains its structure; dynamic, in that its attributes do not remain static; coherent, in that a change in one element of the system causes change in all other elements; and stable, in that it maintains itself within a certain range of values.

Given the evidence adduced concerning the predator-prey relationships in the study area, we may elaborate a model to clarify their respective roles in such a system. This model would contain three principal components:

1. Predation:

a. Wolf predation-the degree of wolf predation pressure can be estimated by the predator-prey ratio, projected pounds of prey taken per year, etc.

b. Human predation (Powers Phase hunters)-the degree of predation pressure can be estimated in terms of projected pounds of prey taken per year, etc.

2. Prey population: white-tailed deer have a very high biotic potential, 63.99\% (Brohn and Robb, 1955).

3. Vegetation base: this defines the carrying capacity, with low oak mast yield years being the specific limiting factor that determines the carrying capacity of the area.

The interaction of these variables is shown in Fig. 6.

With healthy, functioning predator populations present, the deer population would be maintained below subsistence density levels (i.e., below the carrying capacity of the vegetation base). This in turn assures that the vegetation base which supports the prey population will not be degraded. With a stable vegetation base, the deer population remains healthy and at high enough numbers to

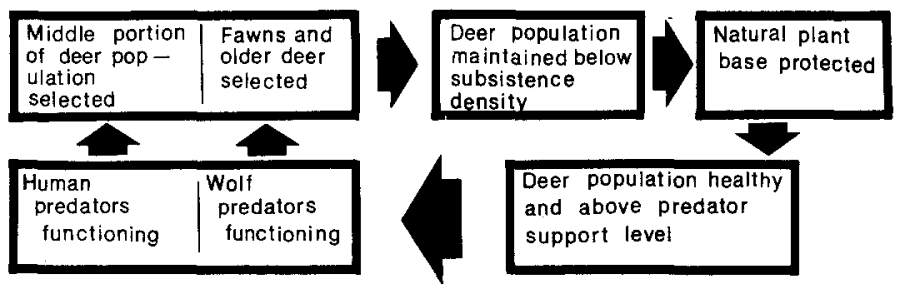

Fig. 6. Flow chart of predator - prey - plant food source systemic model. 


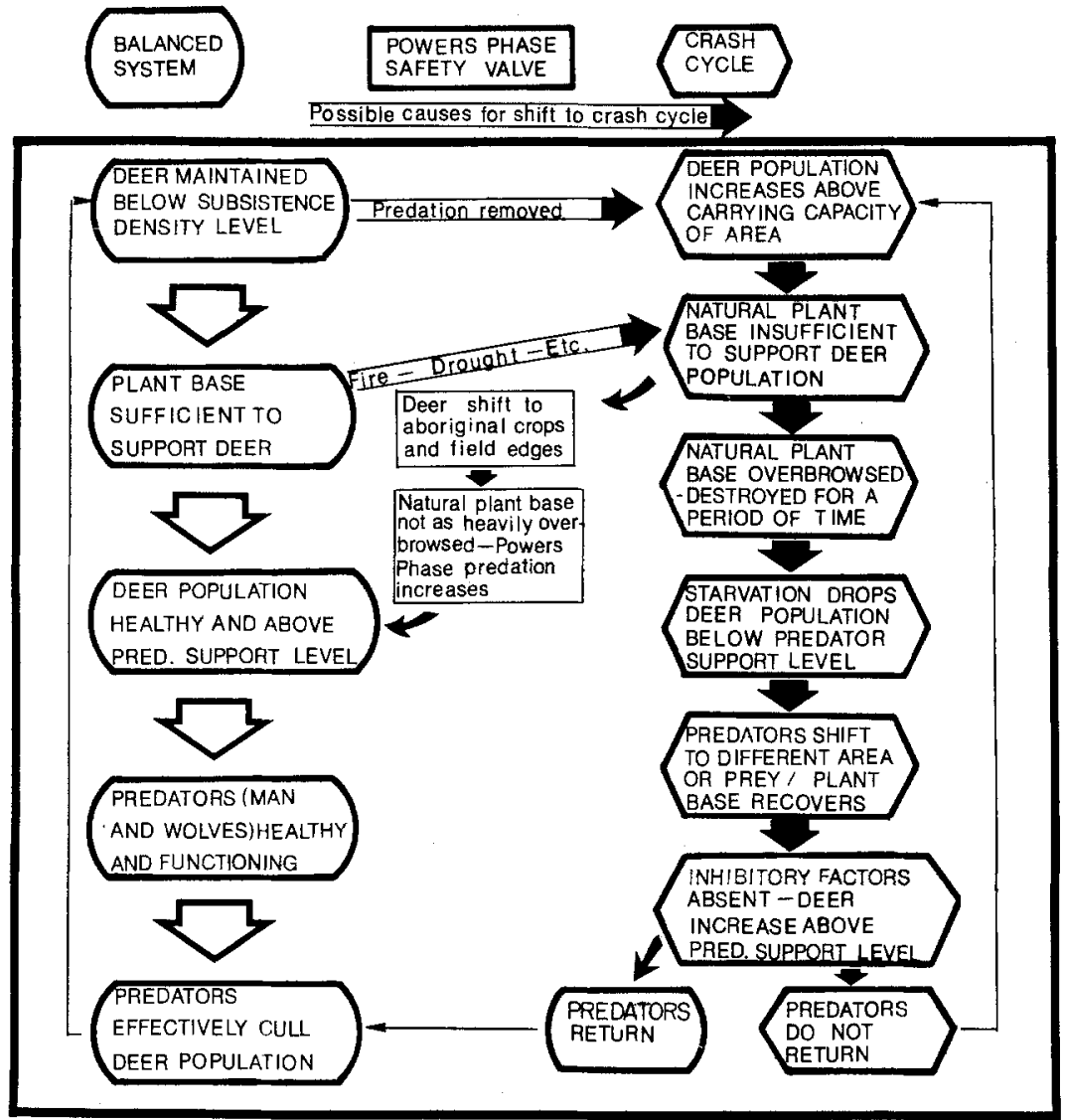

Fig. 7. Interaction of balanced natural system, crash cycle, and Powers Phase safety valve.

support predator populations. This system can be considered as functioning adequately when the deer population is maintained below a subsistence density level.

Any radical change in the status of any one of the three main components could bring on a collapse of the system. Once this has happened, a crash cycle will begin (Fig. 7). When the crash cycle has run its course and the prey population has recovered, the original system will begin to function once again unless, of course, some factor of the system has been permanently altered, in which case the system will never be reestablished. 


\section{ACKNOWLEDGMENTS}

Drs. Kent V. Flannery, Richard I. Ford, James B. Griffin, Dale R. McCollough, and Roy A. Rappaport will, I hope, find ample evidence of the influence of their ideas as they read this article.

\section{REFERENCES}

Brohn, A., and Robb, D. (1955). Age composition, weights, and physical characteristics of Missouri's deer, 1944-1951. Deer Study, Surveys and Investigations Project 13-R, Pittman-Robertson Program, Missouri Conservation Commission.

Dunkeson, R. L. (1958). A study of deer productivity and breeding season. Unpublished State of Missouri Surveys and Investigations Project No. 13-R-12, Work Plan No. 1, Job No. 5.

Elder, W. H. (1965). Primeval deer hunting pressures revealed by remains from American Indian middens. $J$. Wildlife Management 29: 366-370.

Korschgen, L. J. (1962). Foods of Missouri deer with some management implications. $J$. Wildlife Management 26: 164-172.

Mech, L. D. (1970). The Wolf: The Ecology and Behavior of an Endangered Species, American Museum of Natural History Press, Garden City, New York.

Pimlott, D. H. (1967). Wolf predation and ungulate populations. Am. Zoologist 7: 267-278.

Pimlott, D. H., Shannon, J. A., and Kolenosky, G. B. (1969). The Ecology of the Timber Wolf in Algonquin Park. Ontario, Department of Lands and Forests.

Schaller, G. B. (1972a). Predators of the Serengeti: part 2. Natural History 81: 60.

Schaller, G. B. (1972b). The Serengeti Lion, University of Chicago Press, Chicago.

Segelquist, C. A., and Green, W. E. (1968). Deer food yields in four Ozark forest types. $J$. Wildlife Management 32: 330-337.

Segelquist, C. A., Ward, F. D., and Leonard, R. G. (1969). Habitat-deer relations in two Ozark enclosures. J. Wildlife Management 33: 511-521.

Seve-inghaus, C. W. (1949). Tooth development and wear as a criteria of age in white-tailed deer. J. Wildlife Management 13: 195-216.

Steyermark, J. A. (1940). Studies of the vegetation of Missouri. Field Museum of Natural History Botanical Series 9: 349-475.

Steyermark, J. A. (1959). Vegetational history of the Ozark forest. Univ. Missouri Studies, Number 31.

Swanton, J. R. (1946). The indians of the southeastern United States. Bureau of American Ethnology Bulletin 137. 